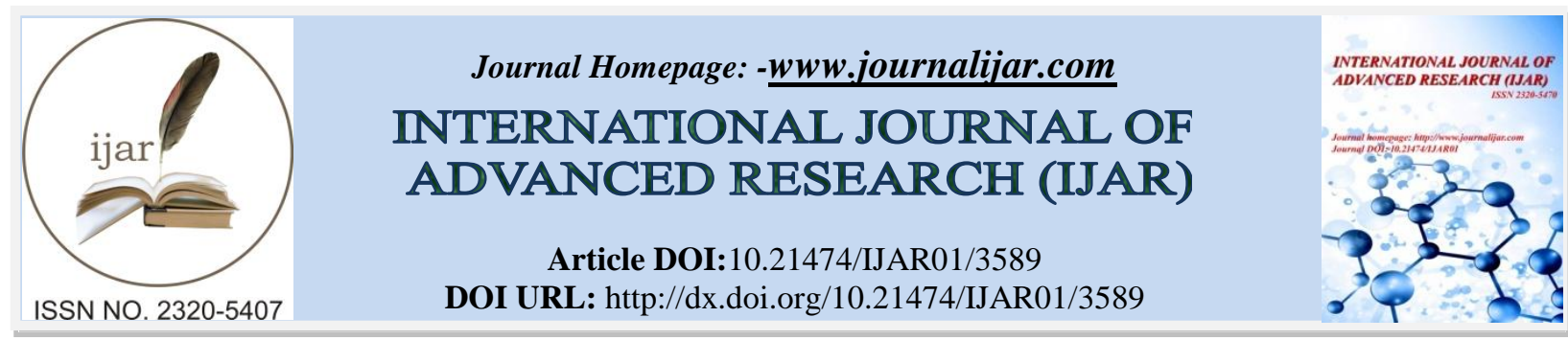

RESEARCH ARTICLE

\title{
DIFFUSION OF PHYSICOCHEMICAL WATER QUALITY PARAMETERS IN A LAB SCALE WATER DISTRIBUTION NETWORK.
}

\author{
Rojacques Mompremier ${ }^{1}$, Óscar Arturo Fuentes Mariles1, Ana Elisa Silva Martínez3 and Martín Rubén \\ Jiménez Magaña ${ }^{2}$. \\ 1. Instituto de Ingenieria, Universidad Nacional Autonoma de Mexico (IIUNAM). \\ 2. Facultad de Estudios Superiores, Aragon. \\ 3. Facultad de Ingenieria, Posgrado, UNAM.
}

\section{Manuscript Info}

(..........................

Manuscript History

Received: 05 January 2017

Final Accepted: 01 February 2017

Published: March 2017

Key words:-

Incomplete mixing, water quality, experimental network, diffusion, physico-chemical parameters

\section{Abstract}

This paper investigates the impact of incomplete mixing at cross junctions on the variation of physicochemical water quality parameters ina lab scale water distribution network. The experimental setup was constructed in the Hydraulic Laboratory of the Engineering Institute at the National Autonomous University of Mexico where a series of experiments with varying inflows, chlorine and natural organic matter concentrations were carried out. Water samples were collected at various sampling points for water quality analysis. The results show how water quality parameters can vary in water distribution network due to the impact of incomplete mixing at cross junctions.

Copy Right, IJAR, 2017,.All rights reserved.

\section{Introduction:-}

The mission of a water distribution network is to provide safe drinking water to the costumers. The Safe Drinking Water Act (SDWA) is the federal law that protects public drinking water. Under the SDWA, the Environmental Protection Agency (EPA) sets standards for drinking water quality and implements various technical and financial programs to ensure drinking water safety. Although most treatment plants are able to achieve these standards, the water distribution systems can be a point where issues regarding pathogens can occur. Variations in hydraulic conditions at junctions can vary the mixing conditions and modify physicochemical parameters of water. Therefore,the objective of this research was to investigate the impact of mixing phenomenon at cross junctions on the diffusion of water quality parameters in the distribution network using a lab scale water distribution network.

\section{Materials and Methods:-}

Experimental setup and preparation:-

In order to study the impact of incomplete mixing at cross junctions on the diffusion of physicochemical water quality parameters in the network, a series of experiments were carried out in a laboratory network system. The experimental setup was divided into three sectors:

1. Sector A consisted of a cross junction pipe system with two inlets (North and West) and two outlets (South and East), Fig 1.

2. Sector B, supplied from East outlet of sector A and;

3. Sector C, supplied from South outlet of sector A.

The experimental setup was constructed with polyvinyl chloride (PVC). The network used pipes of diameter 32 and $38 \mathrm{~mm}$ (Pipe diameters of each segment are shown in the schematic diagrams). 
The system also included.

a. a water reservoir ( $2.12 \mathrm{~m} 3$ of capacity);

b. two storage tanks ( $450 \mathrm{~L}$ of capacity each ) at elevated position for gravity flow;

c. four flow meters (CZ300s model Contazara S.A, Spain) located at each inlet and outlet of the cross junction (sector A) to measure instantaneous flow rate in the system. To ensure the precision of the measurement, a relative error was calculated for each test, a margin of error of $5 \%$ was considered acceptable.

d. ten flow control valves (labelled 1-10), one valve at each inlet and outlet of sector A and three at the entrance of sectors $\mathrm{B}$ and $\mathrm{C}$;

e. ten water valves (labelled a-j), one at each inlet and outlet of sector A and three at the exits of sector B and C;

f. two dosing pumps (BL3-12, HANNA instrument, Mexico) were used to control the chlorine concentration released from the storage tank;

g. an advanced system (CL763, B\&C electronics, Italy) that detects chlorine concentration in the range from 0.1 to $20 \mathrm{mg} / \mathrm{L}$ was installed in sector A (at inlets and outlets). This equipment is designed for inflow continuous measurement of residual chlorine in solution. A different chlorine measurement method was used in sectors B and $\mathrm{C}$ and;

h. a data logger (El-USB-4, Lascar electronics, USA) was connected to each controller. Schematic diagram of the experimental distribution network is shown in Fig 1.

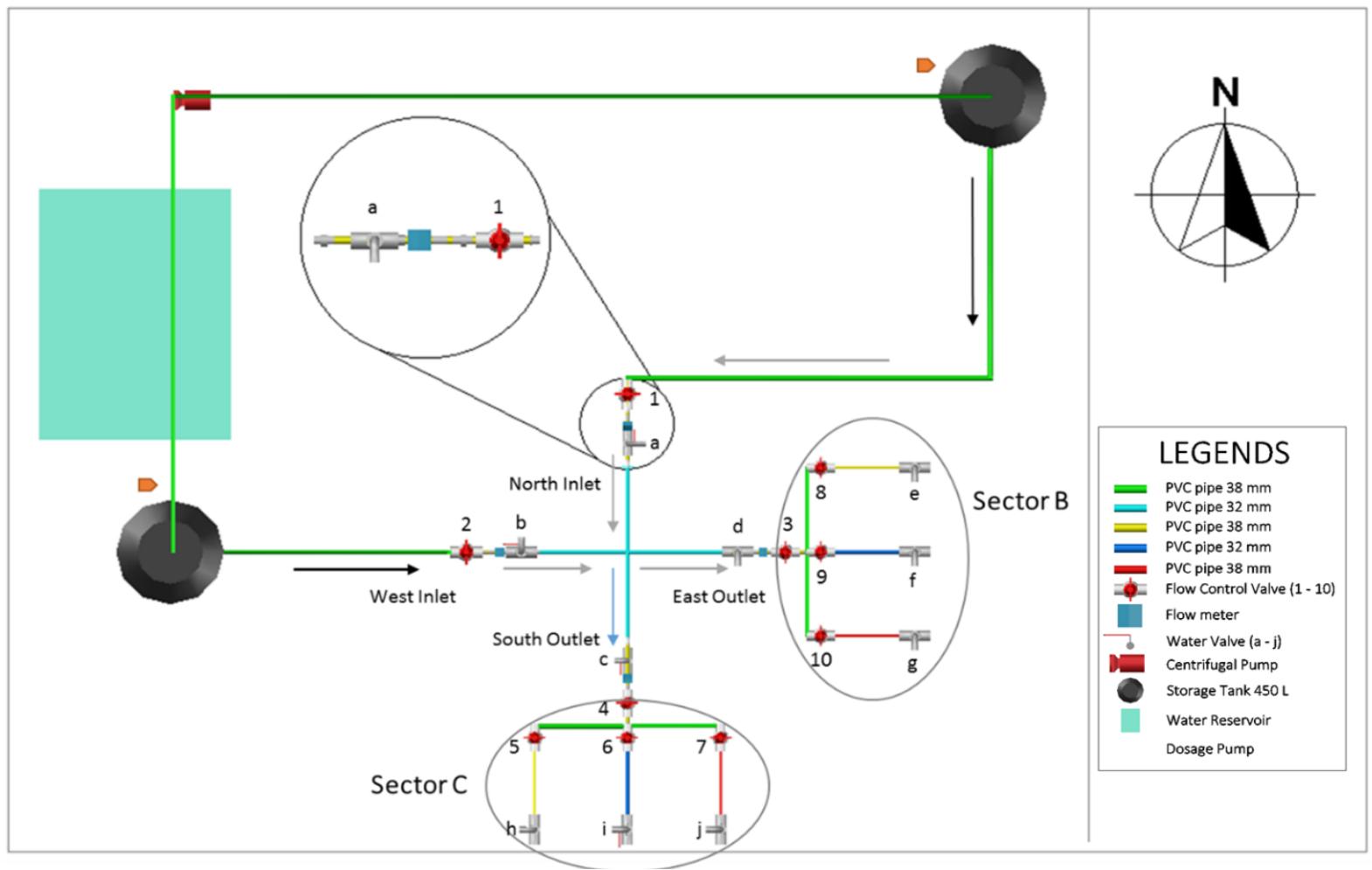

Fig. 1:- Schematic description of the experimental distribution network [sector A inflows at $90^{\circ}$ ]

In order to get a homogeneous mixture of tap water and chemicals (natural organic matter and chlorine), a manual mixer was installed at each storage tank (see Figure 2) 

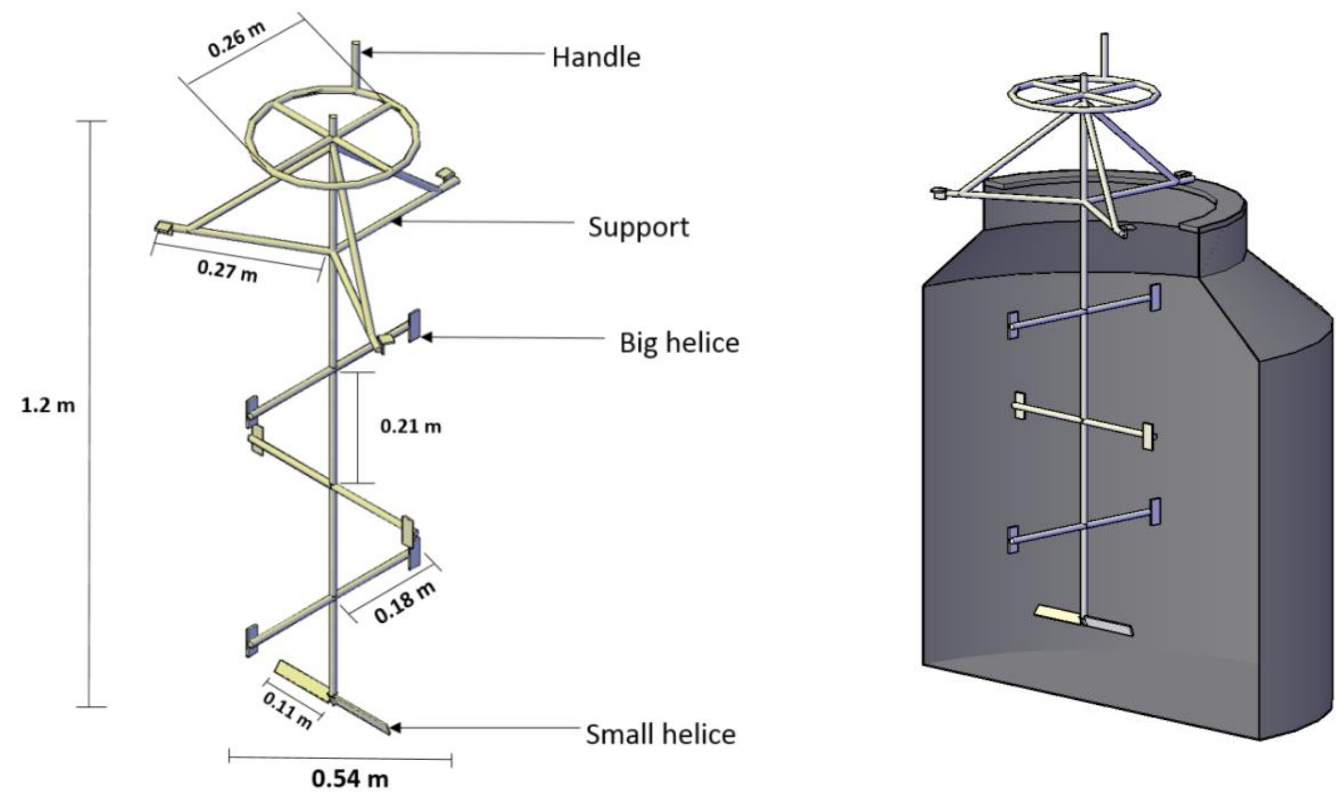

Fig. 2:-Schematic drawing of a manual mixer

\section{Experimental procedure:-}

To carry out the experiments, tap water from the reservoir was pumped to the elevated storage tanks using a 4HME200 centrifugal pump. K-Tonic solution $(1.15 \mathrm{~g} / \mathrm{mL})$ which is a mixing of six compounds such as Total Nitrogen, Urea Nitrogen, K2O water-soluble Potassium, Extract of Total Humic Carbon, Humic Acid Carbon and Fulvic Acid Carbon was used as contaminant agent. Then, $2.73 \mathrm{~mL}$ of K-Tonic solution were added to the North storage tank, which resulted in Total Organic Carbon (TOC) of $0.76 \mathrm{mg} / \mathrm{L}$ and $3.13 \mathrm{~mL}$ of the same solution (Ktonic solution) were added to the West storage tank to get TOC concentration of $0.87 \mathrm{mg} / \mathrm{L}$. About $4.66 \mathrm{~mL}$ and $6.13 \mathrm{~mL}$ of sodium hypochlorite solution (at 13\%) were added to the West and North storage tanks, respectively, which resulted in corresponding chlorine concentrations of approximately $1.35 \mathrm{mg} / \mathrm{L}$ and $1.77 \mathrm{mg} / \mathrm{L}$. The solutions in each tank were mixed using a manual mixer.

The experiment provides varying inflows, varying chlorine and NOM concentrations. Prior to that, flow control valves 1 and 2 (of sector A) were maintained partially opened (approximately 50\% and 75\% respectively) to provide a flow rate of $0.50 \mathrm{~L} / \mathrm{s}$ and $1.14 \mathrm{~L} / \mathrm{s}$ at North and West inlets, respectively (Table 1). Flow control valves (from 6 to 10 of sectors B and C) were totally opened.

Instantaneous flow rates were measured at each inlet and outlet of sector A using the flow meters. Free chlorine concentrations were also measured at each inlet and outlet of sector A. Triplicate samples were collected at each sector for water quality analysis. Five minutes later, flow control valves 5, 6 and 7 as well as water valves e, $\mathrm{f}$, and $\mathrm{g}$ of sector B were closed. Flow control valves $(8,9,10)$ and water valves $(\mathrm{h}, \mathrm{i}, \mathrm{j})$ of sector $\mathrm{C}$ were also closed at the same time. Thus, water was stagnated in sectors B and C. Once completed a period of time of eighteen hours, three samples were collected from pipe segments of sectors B and C for analysis of water quality. The experiment extended for about twenty-four hours.

\section{Analytical Methods:-}

Turbidity was measured using a turbidimeter (2100A, HACH, Mexico). Total organic carbon (TOC), Total Carbon (TC) and Inorganic Carbon (IC) analysis were carried out based on catalytic combustion at $720^{\circ} \mathrm{C}$ using a TOC-L CSH (Shimadzu Corporation, Germany). A 350 mercury thermometer was used to measure water temperature and an M530P (Pinnacle series, USA) unit was used for $\mathrm{pH}$ measurement. A DR 6000 UV-VIS Spectrophotometer with RFID Technology (HACH) was used for absorbance measurement, Total solids and Biochemical Oxygen Demand (BOD) were measured based on the methods for the examination of water and wastewater (APHA 1992), chlorine concentration of samples from sectors $\mathrm{B}$ and $\mathrm{C}$ was measured using the Iodometric titration method based on $\mathrm{Na}_{2} \mathrm{~S}_{2} \mathrm{O}_{3}$ titration. In this case, chlorine concentration was calculatedusing Eq. 1. 


$$
m g C l=\frac{(A \pm B) \times N \times 35450}{m \text { L.sample }}
$$

where:

A mL titration for sample

B mL titration for blank

$\mathrm{N}$ normality of $\mathrm{Na}_{2} \mathrm{~S}_{2} \mathrm{O}_{3}$

\section{Results and Discussion:-}

\section{Sector A:-}

In the experiment, the flow at North inlet was blocked by the incoming water from the West inlet, which had greater flow (Table 1). This forced some of the flow (from North inlet) to get pushed across the junction and exit through the East outlet. This resulted in only slight mixing and had an impact on water quality characteristics at outlets. This results corroborated with those obtained by other researchers such as Chávez et al. 2005, Ho et al. 2007; Ho and O’Rear 2009 and Austin et al. 2008. Water quality parameters of sector A (cross junctions) are presented in Table 1.

Table 1:- Water quality parameters for samples from sector A

\begin{tabular}{|c|c|c|c|c|c|c|c|c|}
\hline Sampling points & $\begin{array}{c}\text { Flow rate } \\
{[\mathbf{L} / \mathbf{s}]}\end{array}$ & $\begin{array}{c}\text { Chlorine } \\
{[\mathbf{m g} / \mathbf{L}]}\end{array}$ & $\mathbf{p H}$ & $\begin{array}{c}\text { Abs } \\
\mathbf{U V}\end{array}$ & $\begin{array}{c}\text { BOD } \\
{[\mathbf{m g} / \mathbf{L}]}\end{array}$ & $\begin{array}{c}\text { Total } \\
\text { Solids } \\
{[\mathbf{m g} / \mathbf{L}]}\end{array}$ & $\begin{array}{c}\text { Turbidity } \\
{[\mathbf{N T U}]}\end{array}$ & $\begin{array}{c}\text { TOC } \\
{[\mathbf{m g} / \mathbf{L}]}\end{array}$ \\
\hline North inlet & 0.50 & 0.70 & 7 & 0.030 & 13.0 & 0.49 & 1.2 & 0.87 \\
\hline West inlet & 1.14 & 0.35 & 7 & 0.026 & 10.5 & 0.36 & 0.9 & 0.76 \\
\hline South outlet & 0.72 & 0.37 & 7 & 0.025 & 9.30 & 0.39 & 1.0 & 0.40 \\
\hline East outlet & 0.92 & 0.53 & 7 & 0.020 & 13.0 & 0.43 & 1.1 & 0.69 \\
\hline
\end{tabular}

\section{Sectors B and C:-}

\section{Effects of incomplete mixing:-}

Because of the incomplete mixing occurred at the cross junctions, physicochemical characteristics of the water varied in the same experimental setup. In the case of sector A, the level of disinfectant at East and South outlets was different. In general, water in the East outlet had higher values of free chlorine, Total Organic Carbon (TOC) levels, total solids, Biochemical Oxygen Demand (BOD), Turbidity that corresponded to the higher level of these parameters in the North storage tank. This is due to the fact that water in East outlet contained mostly water from North inlet and only a slight mix from the West inlet. Samples from sector B (which comes from East outlet of sector A) and sector C (which comes from South outlet of sector A) were collected after an incubation period of eighteen hours and taken to a laboratory for analysis of water quality. Results are presented in Tables 2 and 3 respectively.

Table 2:- Water quality parameters in sector B.

\begin{tabular}{|c|c|c|c|c|c|c|c|c|c|c|}
\hline Sampling points & $\begin{array}{c}\text { Chlorine } \\
{[\mathrm{mg} / \mathrm{L}]}\end{array}$ & pH & $\begin{array}{c}\text { Temperature } \\
{\left[{ }^{\circ} \mathrm{C}\right]}\end{array}$ & $\begin{array}{c}\text { Turbidity } \\
\text { [NTU] }\end{array}$ & $\begin{array}{c}\text { TOC } \\
{[\mathrm{mg} / \mathrm{L}]}\end{array}$ & $\begin{array}{c}\mathrm{TC} \\
{[\mathrm{mg} / \mathrm{L}]}\end{array}$ & $\begin{array}{c}\mathrm{IC} \\
{[\mathrm{mg} / \mathrm{L}]}\end{array}$ & $\begin{array}{l}\text { BOD } \\
{[\mathrm{mg} /]}\end{array}$ & $\begin{array}{c}\text { Total } \\
\text { solids } \\
{[\mathrm{mg} / \mathrm{L}]}\end{array}$ & $\begin{array}{l}\text { Abs } \\
\text { UV }\end{array}$ \\
\hline \multicolumn{11}{|c|}{ Initial water quality parameters of sector $B$} \\
\hline & 0.53 & 7 & 18.6 & 1.1 & 0.69 & 27.81 & 27.41 & 13 & 0.43 & 0.020 \\
\hline \multicolumn{11}{|c|}{ Final water quality characteristic of sector $B$} \\
\hline Sector B & 0.00 & 7 & 18.3 & 1.1 & 0.98 & 27.69 & 26.71 & 6.8 & 0.43 & 0.027 \\
\hline
\end{tabular}

Table 3:- Water quality parameters in sector C

\begin{tabular}{|c|c|c|c|c|c|c|c|c|c|c|}
\hline Sampling point & $\begin{array}{c}\text { Chlorine } \\
{[\mathbf{m g} / \mathbf{L}]}\end{array}$ & $\mathbf{p H}$ & $\begin{array}{c}\text { Temperature } \\
{\left[{ }^{\circ} \mathbf{C}\right]}\end{array}$ & $\begin{array}{c}\text { Turbidity } \\
{[\mathbf{N T U}]}\end{array}$ & $\begin{array}{c}\text { TOC } \\
{[\mathbf{m g} / \mathbf{L}]}\end{array}$ & $\begin{array}{c}\text { TC } \\
{[\mathbf{m g} / \mathbf{L}]}\end{array}$ & $\begin{array}{c}\text { IC } \\
{[\mathbf{m g} / \mathbf{L}]}\end{array}$ & $\begin{array}{c}\text { BDO } \\
{[\mathbf{m g} / \mathbf{L}]}\end{array}$ & $\begin{array}{c}\text { Total } \\
\text { solid } \\
{[\mathbf{m g} / \mathbf{L}]}\end{array}$ & $\begin{array}{c}\text { Abs } \\
\mathbf{U V}\end{array}$ \\
\hline \multicolumn{8}{|c|}{ Initial water quality parameters of sector B } \\
\hline Initial data & $\mathbf{0 . 3 7}$ & 7 & 18.6 & 1.0 & 0.40 & 27.81 & 27.41 & 9.3 & 0.39 & 0.025 \\
\hline \multicolumn{8}{|c|}{ Final water quality characteristic of sector B } \\
\hline Sector C & 0.00 & 7 & 18.3 & 1.1 & 0.62 & 27.94 & 27.72 & 6.9 & 0.39 & 0.020 \\
\hline
\end{tabular}


Results obtained in sectors B and C were aimed at understanding the effect of mixing phenomenon on the diffusion of physicochemical parameters in the network. As it can be seen water quality parameters in sectors B and C such as total organic carbon (TOC), total carbon (TC), inorganic carbon (IC), Biochemical Oxygen Demand, Total solids, absorbance UV, Turbidity were different.

As it can be seen, water quality characteristic measured in both sectors were different due to the incomplete mixing occurred in sector A. This phenomenon is perhaps the most important controlling factor influencing microbial diffusion in water distribution systems.

\section{Conclusions:-}

This study investigated water quality parameters at cross junctions that had incoming flows from different directions $\left(90^{\circ}\right)$. The study showed that incomplete mixing at cross junctions could lead to a heterogeneous diffusion of physicochemical water quality parameters. Results from this study are useful in understanding the effect of pipe configuration in distribution systems and help develop better management systems to address issues related to the variation of water quality parameters in the water distribution system.

\section{Acknowledgments:-}

This research was supported by the Engineering Institute at the National Autonomous University of Mexico, (Instituto de Ingeniería, Universidad Nacional Autónoma de México). Authors would like to thank Livia Elizabeth Sánchez Rueda, Jessica Rodríguez Ruiz, Diana García Aguirre, Denise Reyes García, Tonantzin Ramírez Pérez and Jesus David Ramirez for their participation in the present study.

\section{REFERENCES}

1. APHA. (1992). Standard methods for the examination of water and wastewater. 18th ed. American Public Health Association, Washington, DC.

2. Austin R. G., van Bloemen Waanders B., McKenna S. A. \& Choi C. Y. (2008), Mixing at cross junctions in water distribution systems. II: Experimental study. Journal of Water Resources Planning and Management 134, 295-302. (SAND2007- 4120J).

3. Chávez Z. C., Fuentes Mariles, O. A., Vicente, W. \& Domínguez, M. R. (2005)Simulaciónnumérica de la mezcla turbulenta en el cruce de tuberías (Numerical study of turbulent flow at cross junctions) proceedings of XIX Latin American Congress of hydraulics, Havana, Cuba.

4. Ho C. K. \& Khalsa S. S. (2007) A New Model for Solute Mixing in Pipe Junctions: Implementation of the Bulk Mixing Model in EPANET. In: Presentation to EPA, October 11, 2007 (SAND2007-6646P)

5. Ho C. K. \& O'Rear, L. 2009 Evaluation of Solute Mixing in Water Distribution Pipe Junctions. Journal American Water Works Association. 101, 116-127.

6. Mompremier R., Pelletier G., Mariles Ó. A. F. \& Ghebremichael K. (2015) Impact of incomplete mixing in the prediction of chlorine residuals in municipal water distribution systems. Journal of Water Supply: Research and Technology-Aqua, 64(8), 904-914. 